\title{
Frequency-dependent amplification of the Sanriku tsunamis in Ryori Bay
}

\author{
Yusuke Yamanaka* (10 and Miyuki Nakamura
}

\begin{abstract}
In the present study, the local tsunami amplification observed in Ryori Bay, located on the Sanriku coast of Japan, was investigated using numerical simulations. Large-scale tsunami propagation simulations and tsunami inundation simulations for the bay were systematically conducted to estimate and model the 2011, 1933, and 1896 tsunamis that occurred off the Sanriku coast and which resulted in large run-ups. The simulation results, which are moderately consistent with observations, presented larger run-up heights and inundations for the 1933 and 1896 tsunamis (which followed relatively small earthquakes) compared to those of the 2011 tsunami (which followed a larger earthquake). Furthermore, the frequency analysis indicated that the former two tsunamis comprised higher predominant components. A tsunami inundation simulation using parametrized synthetic waveforms was conducted to identify the contributing factors associated with the large amplification and run-ups. The results indicated that the predominant components are significantly amplified in the bay and the initial decrease in the water surface elevation prior to the primary waves of the two tsunamis leads to an increase in their run-up heights. Furthermore, the simulated waveforms of the tsunamis revealed that the 1933 and 1896 tsunamis had their wavefronts changed into a steep wavefront, i.e., a bore-like wave, during their wave developments in the bay, attributed to shoaling, narrowing bay width, and the nonlinear effect of the wave. These results, therefore, indicate that bores which are known to generate large run-up heights were generated in the bay during the two tsunamis.
\end{abstract}

Keywords: 1933 Showa Sanriku tsunami, 1896 Meiji Sanriku tsunami, Ryori Bay, Frequency dependence, Bore

\section{Introduction}

Located in the Tohoku region and facing the Pacific Ocean, the Sanriku coast of Iwate Prefecture in Japan has experienced large tsunami disasters due to earthquakes that have occurred in the vicinity of the Japan Trench. The 2011 off the Pacific Coast of Tohoku Earthquake that occurred on March 11 was the largest such event ever recorded in the history of Japan. The estimated moment magnitude of the earthquake, Mw, was 9.1 according to the Global Centroid-Moment-Tensor (CMT) Catalogue (Dziewonski and Anderson 1981; Ekström et al. 2012). This earthquake also caused a catastrophic tsunami that resulted in over 15,000 deaths (Mori et al. 2011). The 2011 Tohoku Earthquake Tsunami Joint Survey Group

*Correspondence: yamanaka@coastal.t.u-tokyo.ac.jp

The University of Tokyo, 7-3-1 Hongo, Bunkyo-ku, Tokyo 113-8656, Japan (http://www.coastal.jp/tsunami2011) (TTJS) thoroughly investigated the coastal damage and determined that the heights of the tsunami on the Sanriku coast were substantially large (Mori et al. 2011) because of the proximity of the tsunami source area to the coast, where various intricate bays are located. Many previous studies have proposed source models for the earthquake and the tsunami that facilitate the estimation of the nearshore tsunami behavior, based on various observations (e.g., Ammon et al. 2011; Koper et al. 2011; Fujii et al. 2011; Romano et al. 2012; Yokota et al. 2012; Satake et al. 2013). For example, Satake et al. (2013) developed an earthquake source model that has a length of $500 \mathrm{~km}$ and a width of $200 \mathrm{~km}$ and is based on a waveform inversion technique using the observed tsunami waveforms (Fig. 1a). Wei et al. (2013) estimated the tsunami inundation based on a source model that was developed by the National Oceanic and Atmospheric Administration within $1.5 \mathrm{~h}$ of the 


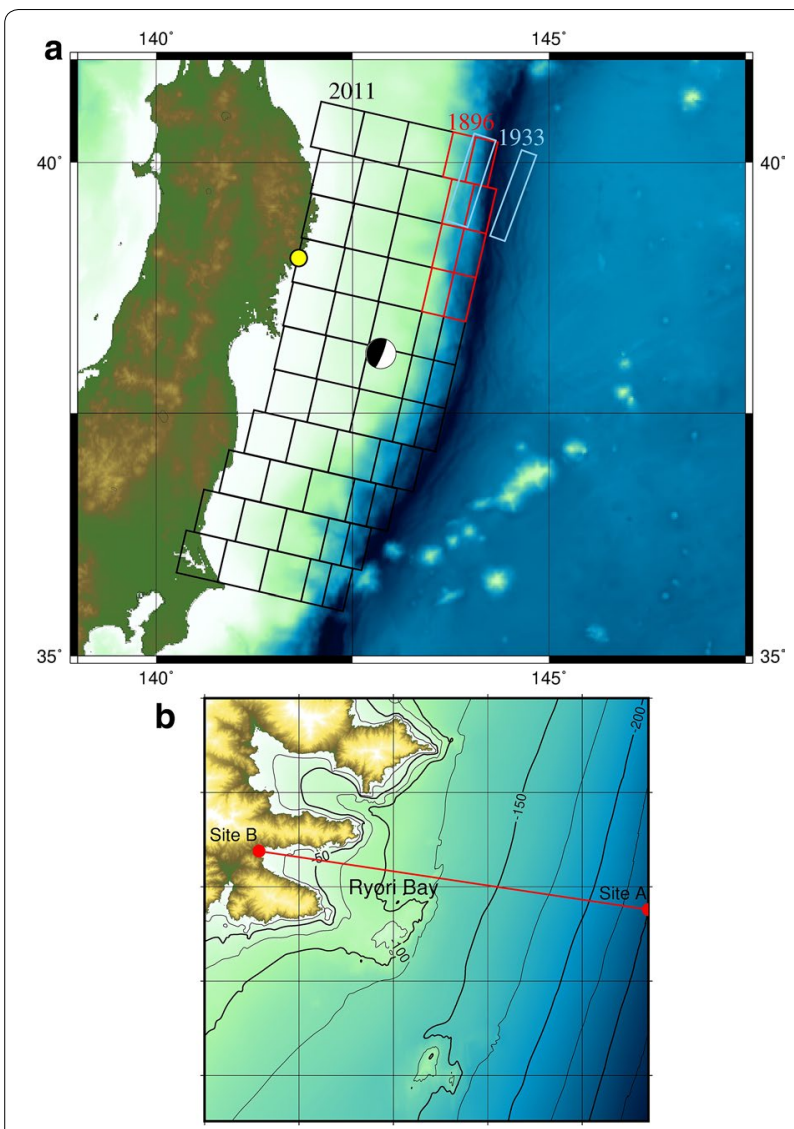

Fig. 1 a The rupture areas of the 2011, 1933, and 1896 earthquakes (the squares of black, light blue, and red) based, respectively, on Satake et al. (2013), Okal et al. (2016), and Satake et al. (2017) and the location of Ryori Bay (yellow circle); $\boldsymbol{b}$ the computation domain for the inundation simulation with the control line along the longitudinal direction of the bay. The focal mechanism of the 2011 earthquake displayed in $\mathbf{a}$ is based on the Global Centroid-Moment-Tensor Catalogue (Dziewonski and Anderson 1981; Ekström et al. 2012). The horizontal coordinates, $X$ and $Y$, at the north-west corner of the domain in $\mathbf{b}$ are $-96,072.0 \mathrm{~m}$ and $82,042.0 \mathrm{~m}$ in the Japanese plane rectangular coordinate system No. 10 and the scale interval for the figure (distance between grid lines) is $5 \mathrm{~km}$

earthquake occurring, and the results were in reasonable agreement with observations. Løvholt et al. (2012) used a numerical simulation to investigate the offshore tsunami profiles and the inundations at ten sites along the Japanese coast. Grilli et al. (2013) estimated the distribution of the run-up height and inundation along the Japanese coast and determined that a finer resolution in the computation domain was necessary to reproduce the large tsunami heights observed on the Sanriku coast accurately. Shimozono et al. (2014) conducted a numerical simulation using the observed tsunami waveforms and showed that short wave components in the tsunami had a large influence on the extreme run-up heights observed in small bays along the Sanriku coast. These studies highlighted the importance of offshore wave characteristics on local inundation and run-up, while some previous studies also outlined the importance of local geometries. Mori et al. (2011), for example, determined that the local inundation heights and run-up heights differed significantly, even in locations having close proximity to each other. This indicates that local coastal geometry plays an important role in describing nearshore tsunami dynamics. Based on their simulated results, Shimozono et al. (2012) also determined that local geometry (such as the funeral bay) and resonance characterized the local tsunami variations observed along the Sanriku coast. Based on an exhaustive review of existing studies, the local nearshore dynamics of the 2011 tsunami were significantly influenced not only by offshore wave characteristics, but also by local geometry. Therefore, it is important to investigate the relationship between tsunami waves and local geometry to understand nearshore tsunami dynamics comprehensively.

The Sanriku coast was severely damaged not only by the 2011 Tohoku tsunami, but also by the tsunamis that followed the 1933 Showa Sanriku and 1896 Meiji Sanriku earthquakes. The 1933 earthquake was the largest earthquake hitherto ever reported among normal fault earthquakes, with $\mathrm{Mw}=8.5$ (Okal et al. 2016), and it caused a large tsunami that resulted in 3000 deaths (Uchida et al. 2016). The 1896 earthquake was an earthquake that generated a relatively larger tsunami, i.e., tsunami earthquake, with $\mathrm{Mw}=8.1$, and it caused the worst tsunami disaster ever in Japan, resulting in approximately 20,000 causalities (Satake et al. 2017; Kanamori 1972). Large run-up heights of 23,29 , and $38 \mathrm{~m}$ were observed at the bayhead in Ryori Bay, located on the Sanriku coast (Fig. 1b), for the 2011, 1933, and 1896 tsunamis, respectively (Kajiura 1977; Miyoshi 1987; Suzuki et al. 2012; TTJS). However, as previously indicated, the moment magnitudes of the 2011, 1933, and 1896 earthquakes were 9.1, 8.5, and 8.1, respectively; thus, because of their smaller moment magnitudes, one would expect the generated offshore tsunamis of the 1933 and 1896 earthquakes to be smaller than those generated by the 2011 earthquake. These observed results indicate that the geometry of Ryori Bay enhanced the run-ups of the 1933 and 1896 tsunamis when compared to the 2011 tsunami. Tsuji et al. (2014) compared historical tsunami heights observed along the Sanriku coast and showed that the heights of the 1933 and 1896 tsunamis were smaller than those of the 2011 tsunami for most of locations on the coast. Tsuji et al. (2014) also concluded that the local geometry was one of the essential factors that explained the local variations in the 1896 and 2011 tsunami heights. Suzuki et al. (2012) focused on the run-up heights of the 
2011 and 1896 tsunamis that were observed in Ryori Bay and determined that differences in source characteristics, such as the existence and location of the large slip area and the seawall, might account for the smaller run-up height of the 2011 tsunami compared to the 1896 tsunami. Kajiura (1977) determined that run-up heights greater than $20 \mathrm{~m}$ in the 1933 tsunami could be explained by non-breaking standing waves, resonance. However, previous studies have not presented an adequate explanation of the large amplification of the 1933 and 1896 tsunamis in the bay following the smaller earthquakes. Therefore, in the present study, the nearshore behavior of the 1933 and 1896 tsunamis in Ryori Bay is investigated in comparison to the 2011 tsunami, using numerical simulations. This is an attempt to determine how these two tsunamis were amplified in a way that caused an enhancement of their run-up heights.

\section{Numerical modeling of tsunami propagation and inundation \\ Source models for the three tsunamis}

Source models for the three tsunamis first need to be determined to conduct a tsunami propagation/inundation simulation. As previously outlined, many source models have been proposed for the 2011 event (e.g., Ammon et al. 2011; Koper et al. 2011; Fujii et al. 2011; Romano et al. 2012; Yokota et al. 2012; Satake et al. 2013); The source model of Satake et al. (2013) was adopted in the present study for the simulation of the tsunami because their source model reproduces better offshore wave profiles of the tsunami. The characteristics of the other two sources have also been investigated based on observed earthquake and tsunami records (e.g., Obana et al. 2017; Satake et al. 2017; Okal et al. 2016; Abe 1973, 1978). Kanamori (1971), for example, proposed a source model of the 1933 event based on observed seismic data. However, Abe (1978) demonstrated that Kanamori's model (1971) was insufficient in explaining the initial motion of the 1933 tsunami that was observed on the Sanriku coast and proposed a new source model. Okal et al. (2016) developed a source model of the event that considered the aftershock distribution according to the earthquake and global tsunami records. Tanioka and Satake (1996a), for example, developed a source model of the 1896 event that reflected a shallow slip at the subducting zone. Tanioka and Seno (2001) discussed the additional sea surface deformation of the 1896 tsunami due to horizontal displacements and bathymetry, using the model proposed by Tanioka and Satake (1996a). Satake et al. (2017) re-estimated the source model based on a tsunami waveform inversion technique and compared the estimated slip amounts with that of the 2011 earthquake. Although there are some uncertainties with understanding the two events, many previous studies concluded that the 1933 earthquake was an outer-rise earthquake (e.g., Okal et al. 2016; Christensen and Ruff 1988) and that the 1896 earthquake was an earthquake that occurred at (or near) the plate interface of the subducting zone (e.g., Satake et al. 2017; Tanioka and Satake 1996a). In the present study, the source models of Okal et al. (2016) and Satake et al. (2017) were adopted for the simulations of the 1933 and 1896 tsunamis, respectively. This is because these studies are expected to facilitate improved nearshore tsunami estimation, as their source models are based on the inverse results of using the observed tsunami heights and waveforms. Each source model consists of a number of segments that reproduce better tsunami waveforms (Fig. 1a). For example, the source model of Okal et al. (2016) consists of two segments located in different areas (primary and auxiliary), which provides a better reproduction of the initial tsunami motion (Uchida et al. 2016). Figure 2 displays the estimated co-seismic vertical displacements due to each source model, based on Okada (1985). As seen in the figure, the 2011 earthquake ruptured areas over a wide range with large slips, resulting in large offshore tsunami heights over these areas. The source areas and displacements for the other two earthquakes were moderate in comparison. Although the centroid locations of their source models were completely different, the magnitudes of tsunamis generated during the two smaller earthquakes should therefore be smaller than that of the 2011 earthquake, as mentioned previously.

\section{Numerical models for tsunami propagation and inundation simulations}

Firstly, a large-scale tsunami propagation simulation is conducted to estimate how and what kind of tsunami propagates into Ryori Bay. Initial water surface deformation due to the earthquakes is assumed to be equal to the co-seismic vertical displacement (Fig. 2); the additional water surface deformation due to the co-seismic horizontal displacement of the ocean bottom and the ocean bathymetry are further considered based on Tanioka and Satake (1996b). The propagation of each deformation is then numerically solved based on a linear longwave model in a spherical coordinate system (Yamanaka et al. 2019). The computation domain is obtained from bathymetry data from the General Bathymetric Chart of the Oceans (GEBCO) with a 30 arc-sec resolution (Weatherall et al. 2015); it has a reflective boundary condition along the shores. A time step of $1.0 \mathrm{~s}$ is determined for the computation. However, some recent studies indicate the importance of the wave dispersion effect to tsunami propagations (e.g., Saito and Frumura 2009; Saito et al. 2014; Hossen et al. 2015; Tanioka et al. 2018). 

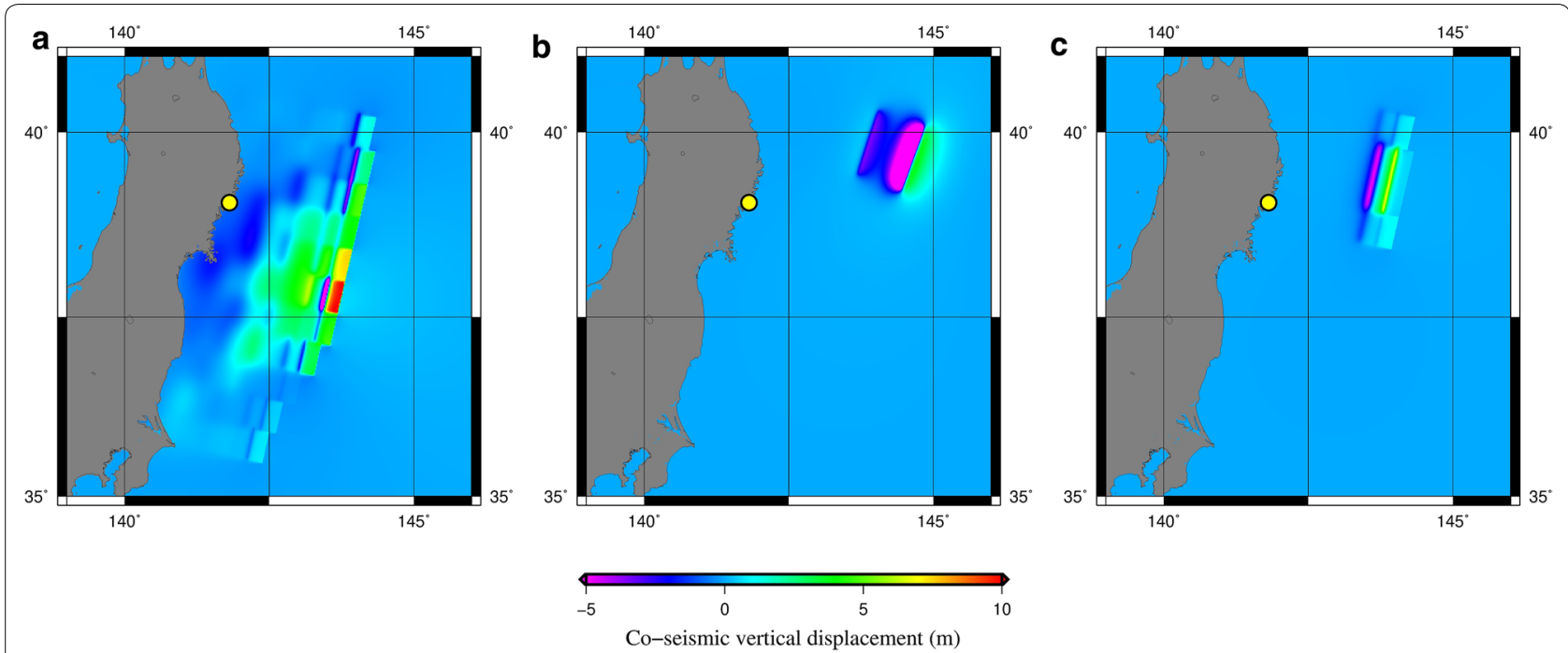

Fig. 2 Estimated co-seismic vertical displacements due to the source models shown in Fig. 1a. a The 2011 earthquake; $\mathbf{b}$ the 1933 earthquake; the 1896 earthquake. The yellow circle indicates the location of Ryori Bay

In particular, according to Tanioka et al. (2018), a normal fault earthquake is capable of generating a substantial dispersive tsunami. Taking the aforementioned into account, a linear dispersive wave model (Yamanaka et al. 2019) is also tested for each propagation, although all the selected source models reflected inverse results based on shallow water theory (i.e., nonlinear or linear long-wave models).

A high-resolution tsunami inundation simulation is then conducted for Ryori Bay based on a nonlinear longwave model (Goto et al. 1997) using a rectangular coordinate system (Fig. 1b). The 1st order up-wind scheme is applied to the advection terms in the momentum equations; the manning's roughness is assumed to be 0.03 and $0.025 \mathrm{~m}^{-1 / 3} \mathrm{~s}$ for land and sea areas, respectively; the moving land-water boundary is modeled the same as Yamanaka et al. (2018) in which the simulated runup height was validated using the analytical solution for a wave run-up. The domain is constructed based on the M7000 Digital Bathymetric Chart provided by the Japan Hydrographic Association and laser profiler measurements from the Japanese Government's Ministry of Land, Infrastructure, Transport and Tourism. It should be noted that the tectonic change due to the co-seismic displacement is not taken into account. In the present study, two domains with different resolutions of 6 and $12 \mathrm{~m}$ are constructed to evaluate the sensitivity of a resolution to the simulation results. The developed computation domains do not account for the coastal structures around the bayhead. As contour lines for bathymetry extend almost in a directly north-south direction and the sources are located off Ryori Bay, all the three tsunamis are expected to enter the bay from due east (Figs. 1b, 2). Therefore, in the present simulation, the change in water surface elevation with time is specified at the east boundary in the domain based on the propagation simulation, and the advection equation with long-wave velocity is solved to determine fluxes at the north, south, and west boundaries of the sea area. Time steps of 0.06 and $0.075 \mathrm{~s}$ are determined for computations with the 6 and $12 \mathrm{~m}$ resolution domains, respectively.

\section{Comparisons of simulated and observed run-up heights}

Figure 3 compares the simulated maximum run-up heights at the bayhead with the observed heights. In the present study, the maximum elevation in terms of the highest ground level inundated by each tsunami was determined as the simulated maximum run-up height. According to Fig. 3, the present model reasonably reproduced the observed run-up height of the 2011 tsunami. Figure $3 \mathrm{a}, \mathrm{b}$ also compares the differences in simulated run-up heights when the different resolutions of the computation domain of $6 \mathrm{~m}$ and $12 \mathrm{~m}$ were applied. The simulation result in the finer resolution domain was better than that in the other resolution domain; however, the difference was insignificant for the simulated run-up heights of the 2011 tsunami. Similar to the simulation results for the 2011 tsunami, those in the finer resolution were better in the case of the 1933 and 1896 tsunamis. However, these differences were also insignificant. The estimation errors for the 1933 and 1896 tsunamis were within $25 \%$. The uncertainty of the source models that were applied may be one of the significant reasons that the simulated run-up heights of the two tsunamis were 

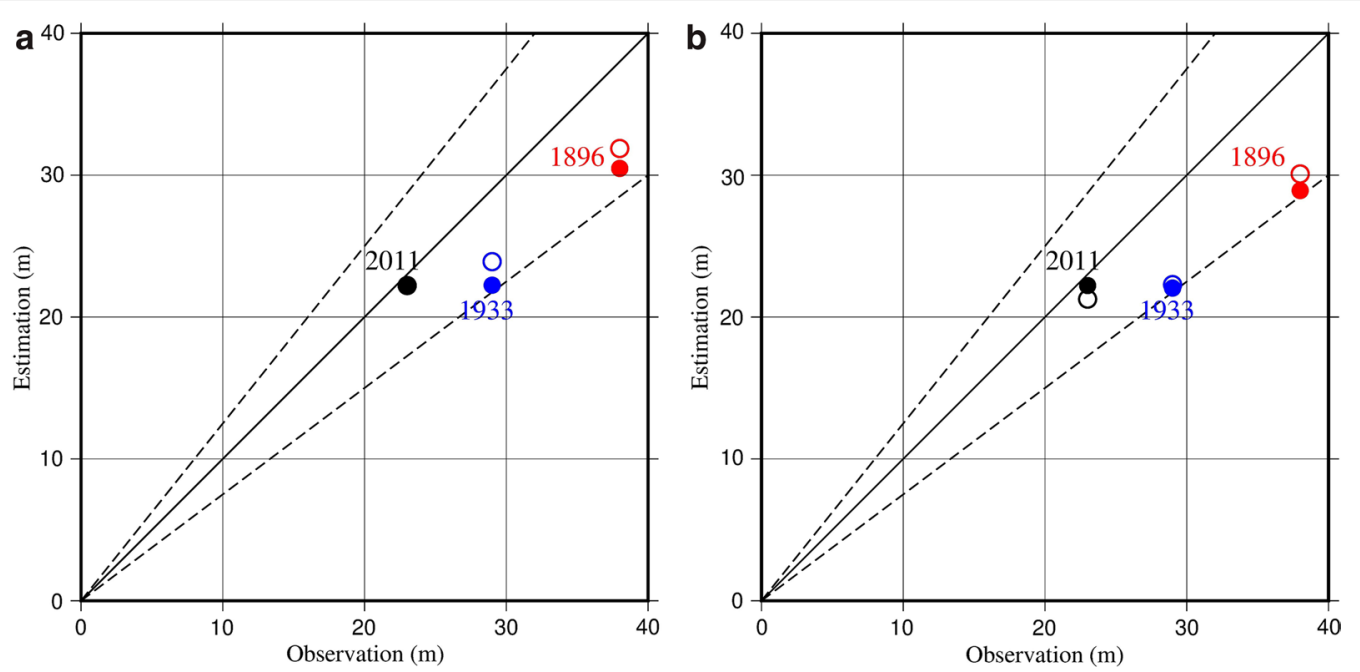

Fig. 3 Comparison of the simulated run-up heights and the observed ones. a The results based on the computation domain with 6-m resolution and $\mathbf{b}$ the results based on the computation domain with 12-m resolution. Black, blue, and red correspond to the 2011, 1933, and 1896 tsunamis, respectively; filled circles and open circles indicate, respectively, the simulation results using the incident waveforms estimated by the linear long-wave model and the linear Boussinesq model. The solid line and the dashed lines indicate $0 \%$ and $25 \%$ errors, respectively

smaller than those that were actually observed. Goda et al. (2015), for example, discussed the influence of the source uncertainties on the local inundation characteristics. However, because very large run-up heights were indeed simulated for the 1933 and 1896 tsunamis, which is moderately consistent with observation, the simulation results will therefore be useful in investigating the details of the amplification and run-up process of the 1933 and 1896 tsunamis in the bay. Additionally, Fig. 3 demonstrates that the dispersive characteristics of the three tsunamis impacted the simulated maximum runup heights. However, these impacts were not significant, and the source models were developed based on the shallow water theory. Therefore, in the present study, the following chapters will outline the investigations into the details of the development of the tsunamis based on the simulation results with the $12-\mathrm{m}$ resolution domain and the incident waveforms simulated in the large-scale tsunami propagation simulation using the linear long-wave model.

\section{The offshore wave profile and amplification of the tsunamis in the bay}

Figure 4a illustrates the waveforms of the three tsunamis at site A for which the still water depth was $250 \mathrm{~m}$ (Fig. 1b), i.e., an incident waveform, simulated based on the large-scale tsunami propagation simulations. This figure demonstrates that the heights of the 1933 and 1896 tsunamis were still smaller than that of the 2011 tsunami. Additional file 1: Figure S1 compared the waveforms simulated by the linear long-wave model and the linear
Boussinesq model and demonstrated that dispersive features of the simulated offshore waveforms were not significant. However, phase differences appeared in each pair of the two waveforms; in particular, shorter wave components in the tsunamis were clearly delayed even in their primary waves, i.e., their first waves, if the dispersive characteristics were considered. Therefore, such shorter wave components were responsible for the differences of the simulated run-up heights for each tsunami (Fig. 3); the dispersive features may be considered for better reproductions of inundation characteristics. Based on the results of the high-resolution tsunami inundation simulation, Fig. $4 \mathrm{~b}$ shows the waveforms of the three tsunamis at the bayhead, i.e., at site B where the still water depth was $1 \mathrm{~m}$ (Fig. 1b), together with the peak holds of the simulated maximum run-up heights. As seen in the waveforms for the 2011 tsunami (Fig. 4b), the water surface elevation gradually increased to over $15 \mathrm{~m}$ with a short period of fluctuation within $40 \mathrm{~min}$ after the earthquake. The shorter period waves were able to generate the large standing waves of the latter wave that were identified approximately $45 \mathrm{~min}$ after the earthquake, which correspond to resonant oscillation. Yamanaka et al. (2013), for example, concluded that the 2011 tsunami formed a standing wave near the bayhead based on the analysis of recorded video footage and the numerical simulation. Yamanaka et al. (2019) determined that the standing wave was one of the waves dominated by the bay-scale resonance. In contrast, the peak values of the water surface elevations during the primary waves in the 1933 and 1896 tsunamis at site B were comparable to 

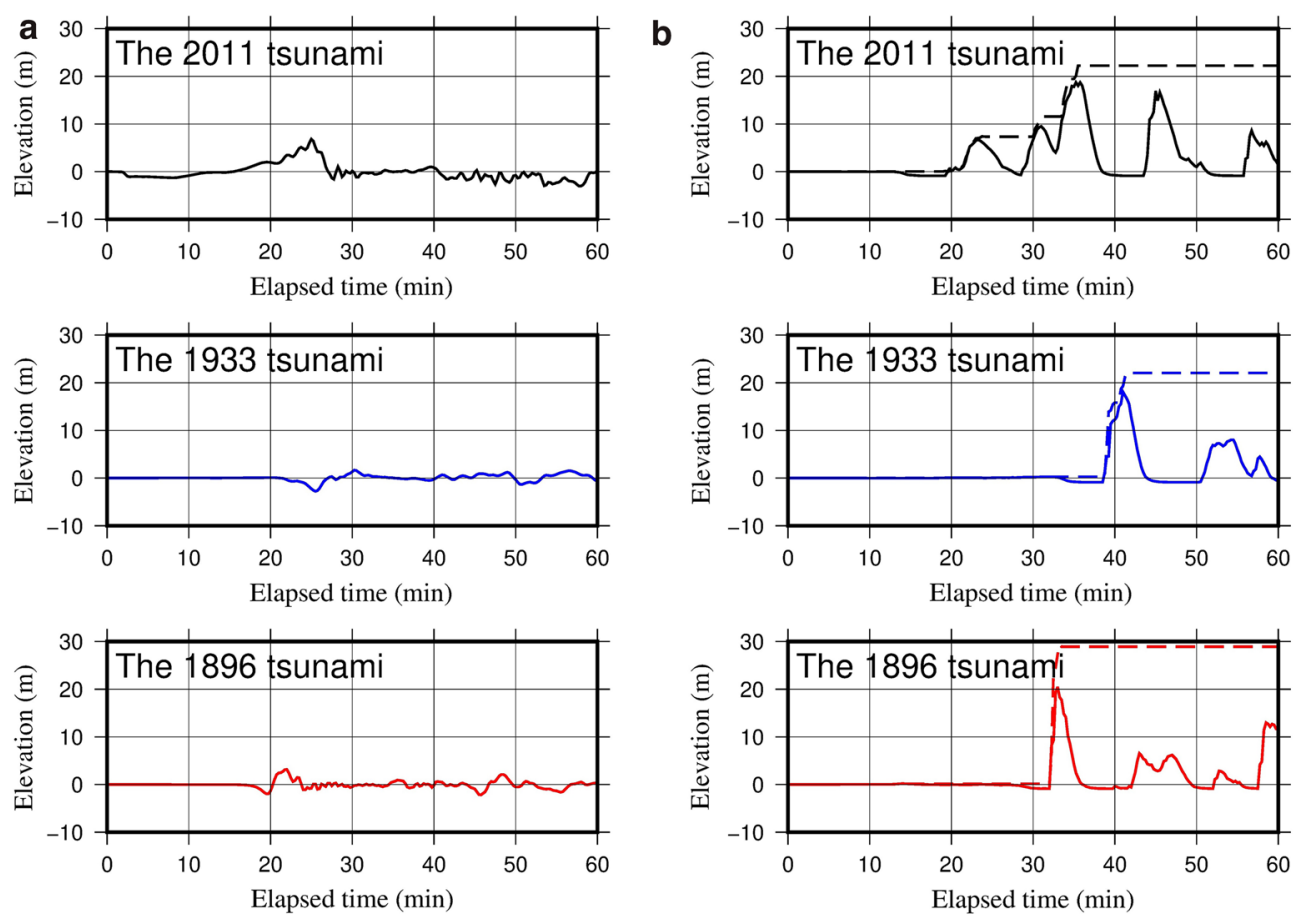

C

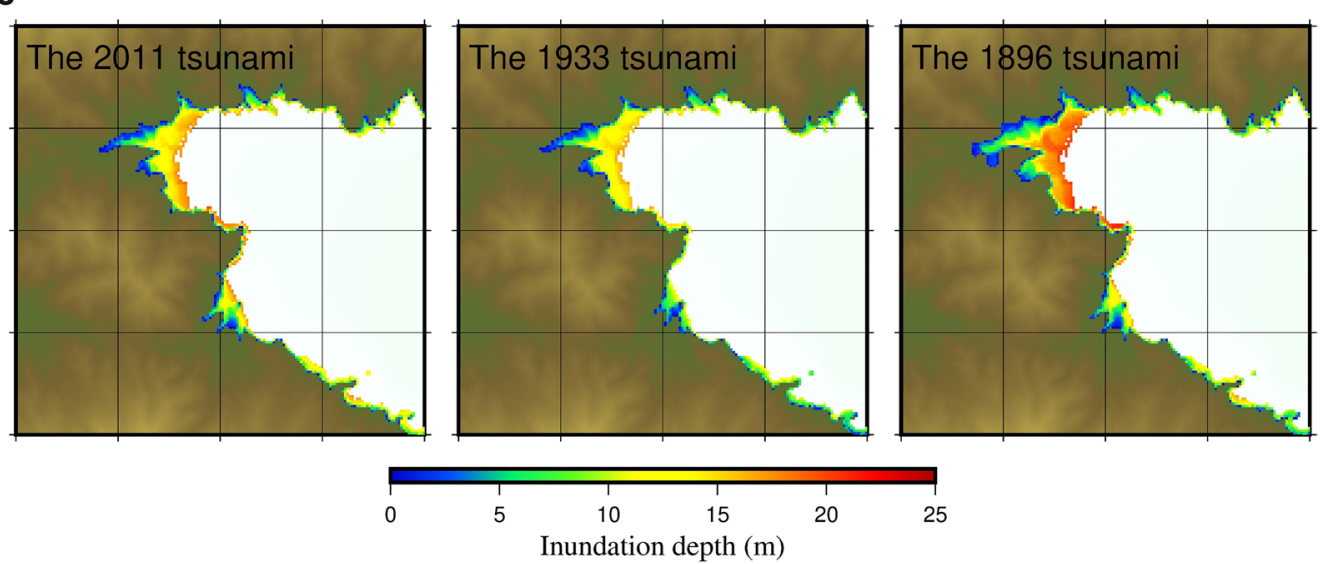

Fig. 4 a The time-series of the simulated water surface elevations for site A specified in Fig. 1b; $\mathbf{b}$ the time-series of the simulated water surface elevation (solid line) for site B specified in Fig. $1 \mathrm{~b}$ and the peak hold of the maximum run-up height (dashed line); c distribution of the maximum inundation depths in the vicinity of the bayhead. The horizontal coordinates, $X$ and $Y$, at the north-west corner of the domain in $\mathbf{c}$ are $-103,572.0 \mathrm{~m}$ and $84,042.0 \mathrm{~m}$ in the rectangular coordinate system and the grid-line interval for the figure is $500 \mathrm{~m}$

that of the 2011 tsunami, whereas their offshore tsunami heights were significantly smaller (Fig. 4a, b). Furthermore, the run-up heights for the two tsunamis were maximized during their primary waves, similar to the case of the 2011 tsunami. Figure 4c displays the distribution of the maximum inundation depth in the vicinity of the bayhead after the primary wave and indicates that the three tsunamis have similar inundation areas. Additionally, the inundation depth for the 1896 tsunami was significantly greater than that of the 2011 and 1933 tsunamis.
Therefore, these results indicate that a relatively small offshore tsunami is capable of being significantly amplified due to the nearshore bay geometry, thereby causing a large inundation. Figure 5 shows the Fourier amplitudes of the incident waveforms at site A, corresponding to the waveforms described in Fig. 4a. According to the amplitudes, the predominant frequency component corresponding to the maximum Fourier amplitude was approximately $2.6 \times 10^{-4} \mathrm{~Hz}(64 \mathrm{~min})$ for the 2011 tsunami, while the components were approximately 


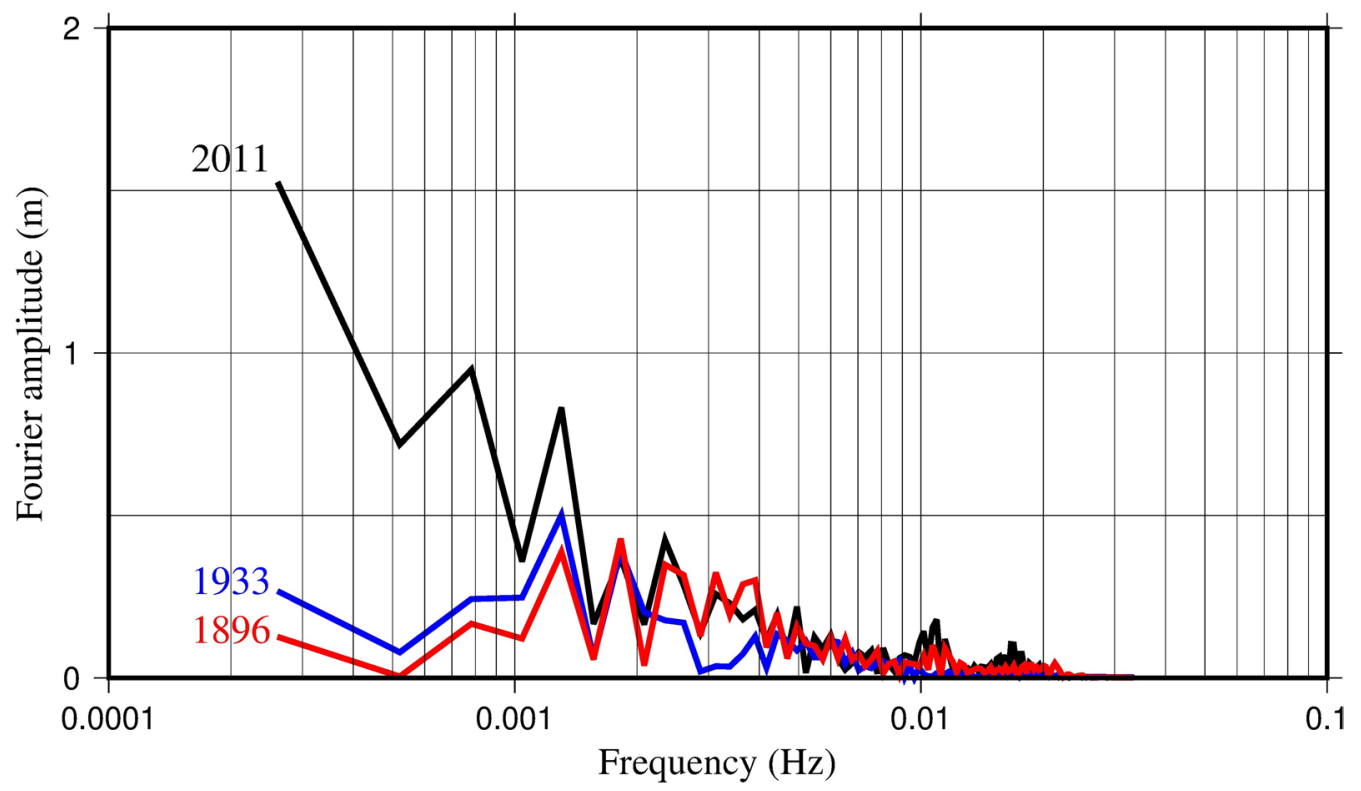

Fig. 5 Fourier amplitudes of the water surface elevation changes of the 2011, 1933, and 1896 tsunamis at site A specified in Fig. 1b (black, blue, and red), corresponding to the waveforms of Fig. $4 \mathrm{a}$. The length and time resolutions of the waveforms are $1 \mathrm{~h}$ and $15 \mathrm{~s}$, respectively, and the data length for the Fourier analysis is $2^{8}$

$1.3 \times 10^{-3} \mathrm{~Hz}(13 \mathrm{~min})$ and $1.8 \times 10^{-3} \mathrm{~Hz}(9.3 \mathrm{~min})$ for the 1933 and 1896 tsunamis, respectively. These relatively high-frequency components are due to the confined rupture dimensions of the earthquakes, as well as their source depths (Fig. 1a). In particular, their short fault widths would be largely responsible for these because the rupture of fault with a shorter width generates a tsunami with a shorter wave period. Taking these results into account, the differences in the predominant components should therefore be an essential factor in explaining each of the nearshore tsunami behaviors in the bay.

\section{Analysis of the factors that contribute to the observed large run-up heights Numerical experiment}

A numerical experiment was conducted for Ryori Bay using an incident waveform and the same computation conditions for the high-resolution tsunami inundation simulation described in Chapter 2. The contributing factors for the generation of the large run-up heights observed in the 1933 and 1896 tsunamis, and their influences, are then investigated based on these results and the simulation results for the 1933 and 1896 tsunamis described in Chapters 2 and 3. For the experiment, the incident tsunami waveform was newly introduced as a product of the sinusoidal and the Gaussian functions and expressed using the following equation (Shimozono et al. 2014):

$$
\eta_{0}(t)=A_{0} \cos \left\{\omega\left(t-t_{0}\right)\right\} \exp \left\{-\frac{\omega^{2}\left(t-t_{0}\right)^{2}}{2 \alpha^{2}}\right\}
$$

where $\eta_{0}$ is the water-surface elevation at the offshore boundary, $A_{0}$ is the amplitude of the incident tsunami, $\omega=2 \pi / T$ is the angular frequency with a wave period, $T, t_{0}$ is the time when the peak of the primary wave appears, and $\alpha$ is a coefficient. Equation (1) with $\alpha=1$ represents a wave near the one up-pulse. For $\alpha=2$, this equation represents a wave in which the initial decrease in the water surface elevation prior to the up-pulse is further enhanced (Fig. 6a). The peak values of the incident waveforms in the 1933 and 1896 tsunamis were smaller than $4 \mathrm{~m}$; in addition, the predominant components for the tsunamis were approximately $1.3 \times 10^{-3} \mathrm{~Hz}$ and $1.8 \times 10^{-3} \mathrm{~Hz}$, respectively (Fig. 5). To investigate how sensitive the run-up height is to changes in wave amplitude and wave period, the waveforms based on Eq. (1) with the variable values of $\alpha(=1$ and 2$), A_{0}(=3 \mathrm{~m}$ and $4 \mathrm{~m})$, and $T(=5,7,10,15,20,30$, and $40 \mathrm{~min})$ were then entered at the incident boundary to be propagated into the bay.

\section{Generation mechanism of the large run-up heights}

Figure 6b, c summarizes the results of the numerical experiment and demonstrate that the run-up heights tended to become larger as the wave period is reduced. This is because of the frequency dependence of wave development in Ryori Bay; wave development associated 

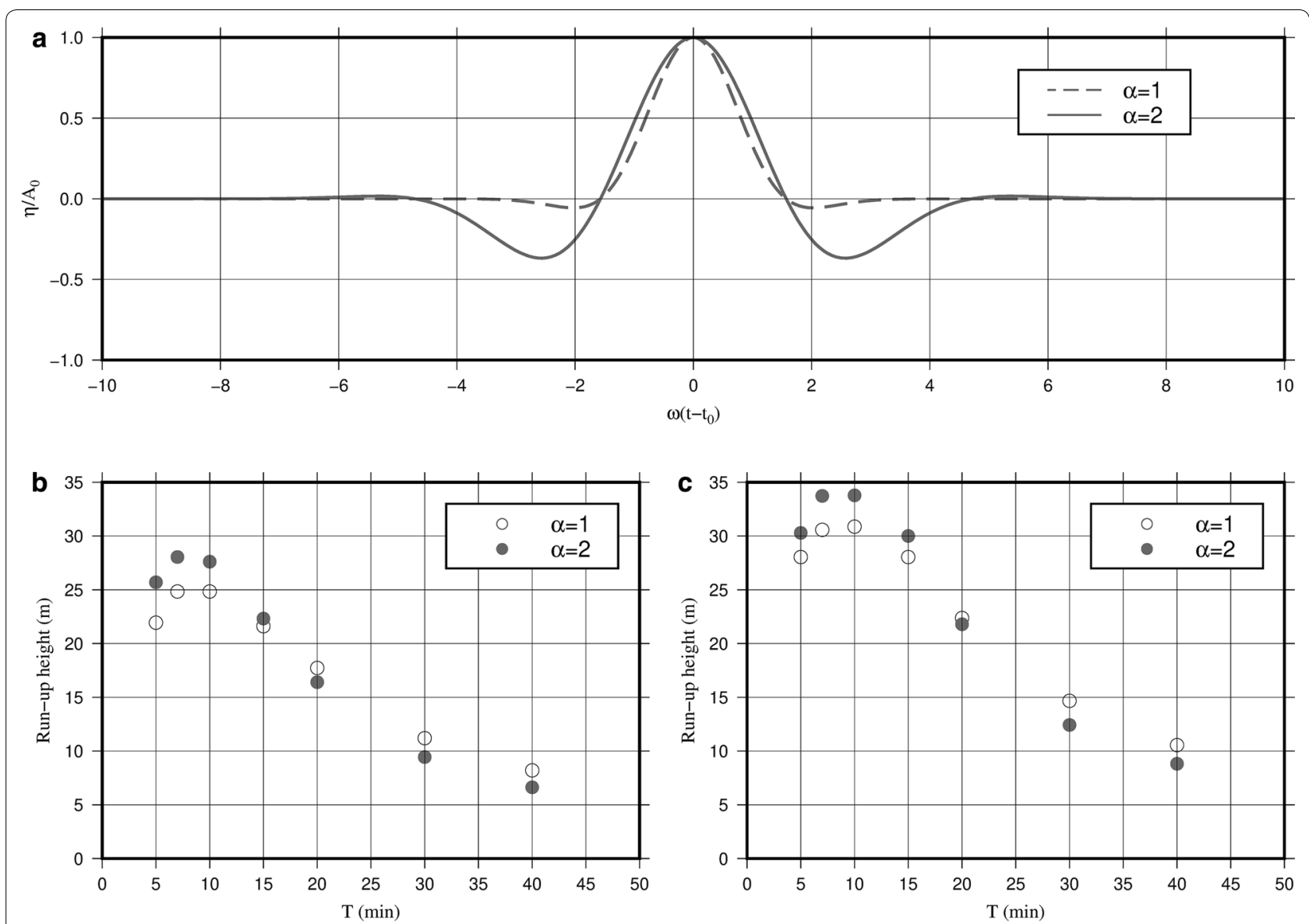

Fig. 6 a The incident waveforms based on Eq. (1) with $a=1$ and 2; $\mathbf{b}$ the simulated run-up heights based on the incident waveforms with $A_{0}=3 \mathrm{~m}$; c the simulated run-up heights based on the incident waveforms with $A_{0}=4 \mathrm{~m}$

with shoaling, narrowing bay width, and the nonlinear effect increases as the wave period becomes shorter [e.g., Yamanaka et al. (2018)]. Figure 6b, c also demonstrates that the simulated run-up height is much more sensitive to changes in the incident wave period than the incident wave amplitude. According to the figures, the simulated run-up heights appeared to peak within a period ranging from approximately 7 to $10 \mathrm{~min}$. Further, the predominant components of the 1933 and 1896 tsunamis, $1.3 \times 10^{-3} \mathrm{~Hz}(13 \mathrm{~min})$ and $1.8 \times 10^{-3} \mathrm{~Hz}(9.3 \mathrm{~min})$, were very close to this range. Thus, the predominant frequency characteristics of the two tsunamis that were amplified by the bay geometry had the greatest influence on the observed large run-up heights. Consequently, these tsunamis were capable of causing significant damage in the bay. The incident waveforms with $\alpha=2$ within this range, compared to waveforms with $\alpha=1$, generated higher run-up heights. Equation (1) with $\alpha=2$ introduces an initial decrease in water surface elevation prior to the up-pulse wave in the incident waveform (Fig. 6a). As both the 1933 and 1896 tsunamis involved an initial decrease in the water surface elevations (Fig. 4a and Additional file 1: Figure S1), the run-up of the two tsunamis would, therefore, be further enhanced by the decrease resulting in the increase of the wave height. Tadepalli and Synolakis (1994), for example, showed that a leading depression $\mathrm{N}$-wave further enhances the run-up height compared to a leading elevation $\mathrm{N}$-wave. The ratio of the negative peak value of the water surface elevation prior to the primary wave and the positive peak of the primary wave was approximately -0.4 for an incident waveform with $\alpha=2$. The values for the 1933 and 1896 tsunami waveforms at site A that correspond to the waveforms in Fig. 4a were -1.3 and -0.6 , respectively. The enhancement of the run-up heights of the two tsunamis due to the initial decrease in the water surface elevation could, therefore, be larger than that expected from the results of the numerical experiment. According to Fig. 6b, c, the incident waveforms with $\alpha=2$, in contrast, generated lower run-up heights compared to waveforms with $\alpha=1$ when the wave period was longer than $20 \mathrm{~min}$. The numerical simulation with an incident waveform having $\alpha=2$ and 
a longer wave period tend to produce a water surface elevation for the entire computation domain decrease, prior to the primary wave. That might be why the runup heights were smaller in the case of $\alpha=2$ and with the wave period longer than 20 min.

Figure 7 illustrates the temporal waveforms of the 2011, 1933, and 1896 tsunamis during their primary waves along the control line (Fig. 1b). As evident in the figure, the wavefront of the 2011 tsunami has a mild slope because the predominant wave period was quite long. In contrast, the wavefront of the other two tsunamis gradually became steep and generated a bore-like wave around the bayhead under the influence of the narrowing bay width in addition to the shoaling and the nonlinear effect of the wave. Thus, the run-up heights of the two tsunamis observed in the bay might be enhanced as a result that a bore contributing to the generation of large run-ups (e.g., Yeh 1991; Hibberd and Peregrine 1979) was generated. However, shallow water theory does not accurately reproduce a bore propagation because it evolves into transient waves such as breaking bore, undular bore, and waves involving soliton fission that are strongly associated with wave dispersion and wave breaking, as well as nonlinearity of the wave, depending on the characteristics of the wave and the geometry (e.g., Losada et al. 1989; Liu and Cheng 2001; Madsen et al. 2008; Pelinovsky et al. 2015; Sriram et al. 2016). Additionally, the 1st order up-wind scheme applied to the advection terms in the
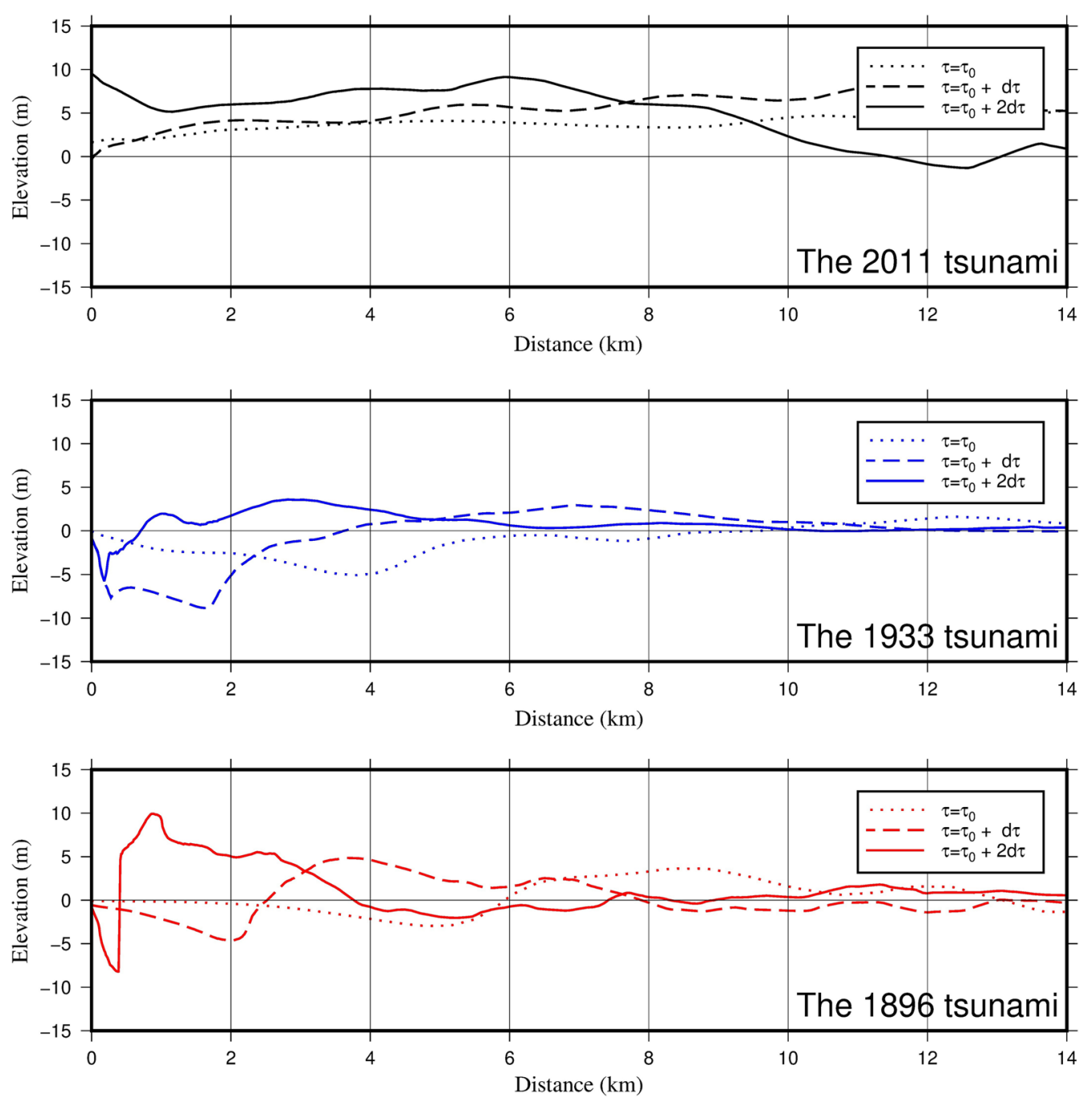

Fig. 7 The temporal tsunami waveforms during the primary wave along the control line specified in Fig. 1b. The horizontal distance is positive towards the offshore from site B. The dotted, dashed, and solid lines represent the waveforms observed at times $\tau=\tau_{0}, \tau_{0}+\mathrm{d} \tau$, and $\tau_{0}+2 \mathrm{~d} \tau ; \mathrm{d} \tau$ is $150 \mathrm{~s}$ and $\tau_{0}$ for the 2011, 1933, and 1896 tsunamis are 1560, 2010, $1605 \mathrm{~s}$, respectively 
present model reduces the acceleration of the wavefront and wave height due to the numerical diffusion effect. Furthermore, the surge front would appear on wave runup process if the bore was generated in the vicinity of the bayhead; however, the moving boundary condition of the present model was not validated for that scenario. These reasons, in addition to uncertainties in the tsunami sources and the elevation model, could potentially account for the underestimation of the simulated run-up heights for the 1933 and 1896 tsunamis.

\section{Discussion}

\section{Frequency-dependent amplification characteristics for the 2011, 1933, and 1896 tsunamis}

In the present study, a transfer function was introduced, similar to that applied by Yamanaka et al. (2018), to estimate the frequency dependence of the wave amplification in Ryori Bay, based on the simulated waveforms of the three tsunamis. The function, which describes the wave amplification ratio, was calculated as the ratio of the Fourier amplitudes of the waveforms at sites B and A, i.e., at the bayhead and offshore on the incident boundary. The value was determined to be 1.0 at a frequency component where the Fourier amplitude at site A was less than $0.05 \mathrm{~m}$ (Fig. 5). In the present study, we only focused on the function with components lower than $3.3 \times 10^{-3} \mathrm{~Hz}$, i.e., longer than $5 \mathrm{~min}$, because the simulated results with time and spatial resolutions of $15 \mathrm{~s}$ and $12 \mathrm{~m}$, respectively, may be too coarse to investigate the values for higher components. Figure 8 demonstrates that the functions exhibited a similar trend that was independent of the tsunamis, in that the value peaked at a frequency component of approximately $1.6 \times 10^{-3} \mathrm{~Hz}(10 \mathrm{~min})$. This component was within the range in which the run-up heights simulated in the numerical experiment were significantly amplified. Therefore, this method will be useful to identify which component is sufficiently amplified to cause large inundations and run-ups on each coast. One of the other important features of the functions was that the value gradually increases as the frequency increases; however, there was a rapid decrease at approximately $2.0 \times 10^{-3} \mathrm{~Hz}$, and the value remained relatively low for components higher than $2.0 \times 10^{-3} \mathrm{~Hz}$. Figure $6 \mathrm{~b}, \mathrm{c}$ also displays similar characteristics, in that the simulated run-up heights became larger as the wave period became shorter, and then decreased at a wave period shorter than $7 \mathrm{~min}$. The most likely explanation may be wave refraction in the bay. Shimozono (2016) analytically examined long-wave propagation in converging bays and showed that waves with relatively short periods are significantly refracted during their propagation into bays. To investigate the wave refraction effect, Fig. 9 illustrates the distributions of the maximum water surface elevation in the bay based on the results of the numerical experiment. The maximum values seem to gradually become large from the bay entrance towards the bayhead in both cases for periods of 5 and $15 \mathrm{~min}$ (Fig. 9a, b). However, the distribution for the case of $5 \mathrm{~min}$ showed significant variation in the lateral direction of the bay, while that for the case of 15 min exhibited an insignificant variation. To investigate these variations quantitatively, the maximum values along some of the control lines specified

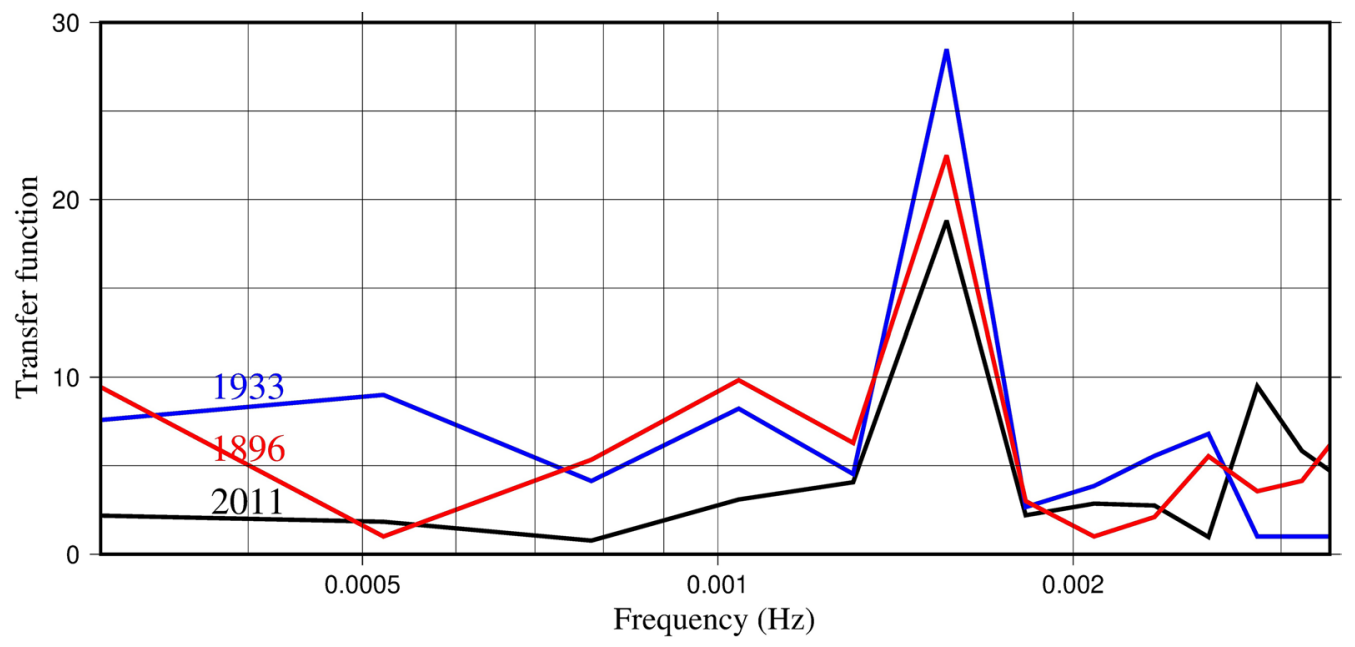

Fig. 8 The transfer functions computed by the ratio of the Fourier amplitudes for site B over site A, specified in Fig. 1b. The black, blue, and red lines represent results for the 2011,1933, and 1896 tsunamis, respectively. The length and time resolutions of the waveforms are $1 \mathrm{~h}$ and $15 \mathrm{~s}$, respectively, and the data length for the Fourier analysis is $2^{8}$ 


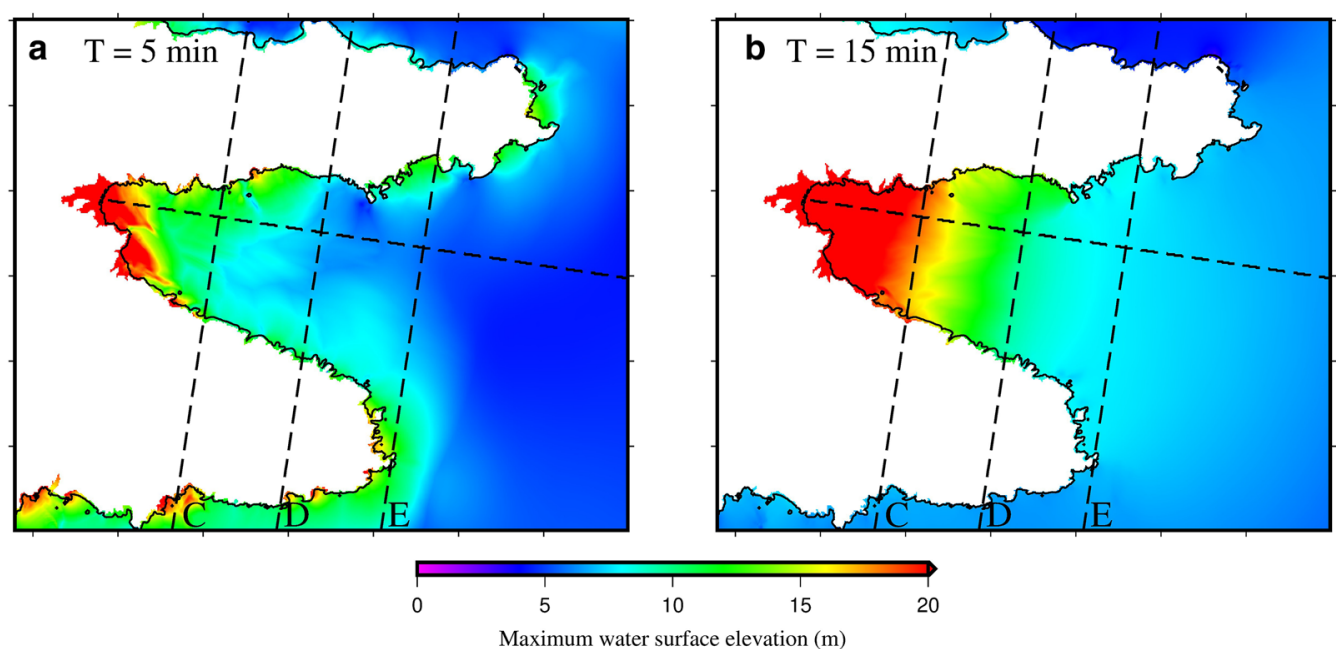

C
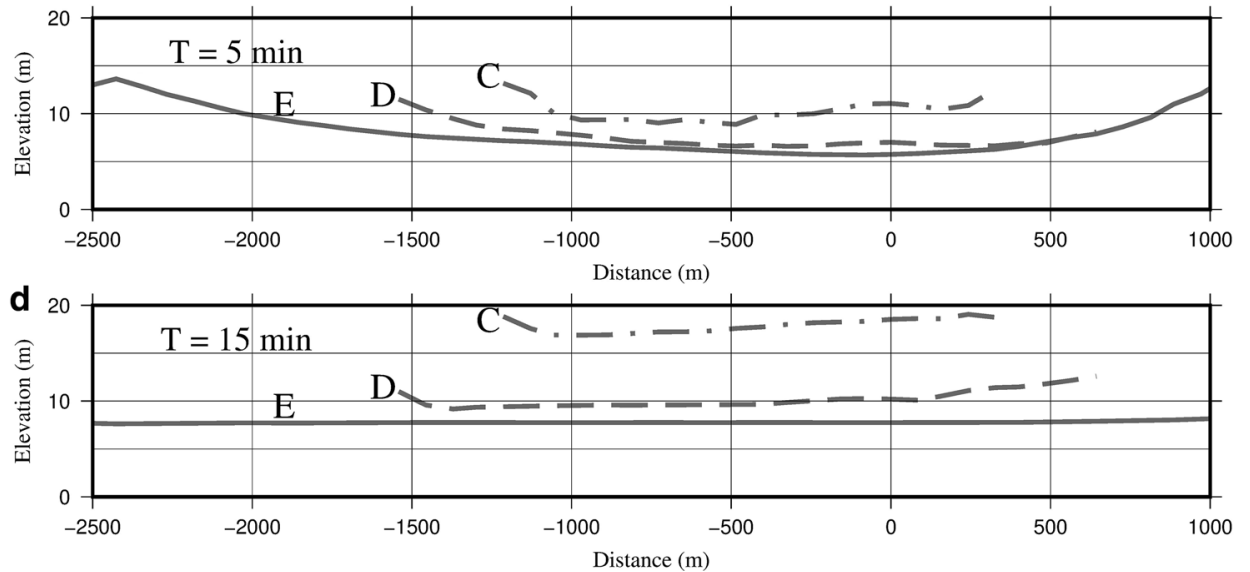

Fig. 9 a The distribution of the maximum water surface elevation based on the incident waveform with $a=2, A_{0}=4 \mathrm{~m}$, and T=5 min; $\mathbf{b}$ the distribution of the maximum water surface elevation based on the incident waveform with $a=2, A_{0}=4 \mathrm{~m}$, and $T=15 \mathrm{~min}$; $\mathbf{c}$ the profile of the water surface elevations along the control lines in the lateral direction of the bay based on the result of $\mathbf{a}$; $\mathbf{d}$ the profile of the water surface elevations along the control lines in the lateral direction of the bay based on the result of $\mathbf{b}$. The horizontal coordinates, $X$ and $Y$, at the north-west corner of the domain in $\mathbf{a}, \mathbf{b}$ are $-102,060.0 \mathrm{~m}$ and $83,830.0 \mathrm{~m}$ in the rectangular coordinate system and the tick interval for the figure is $1 \mathrm{~km}$; the control line in the longitudinal direction of the bay and the three control lines in the lateral direction of the bay (lines C, D, and E) are shown as black dashed lines; the shore lines are shown as black solid lines. The distance is positive towards the northern side along the control line for the longitudinal direction

in Fig. 9a, b were extracted (Fig. 9c, d). As seen in the case of $T=5 \mathrm{~min}$ (Fig. 9c), the maximum water surface elevations along the control lines exhibited significant variations and became locally higher at the boundary between the inundated and non-inundated areas. In the case of $T=15 \mathrm{~min}$ (Fig. 9d), the local concentration was relatively smaller than that in the case of $T=5 \mathrm{~min}$ and little variation was found along the offshore control line, i.e., the line E. Considering these results together with the results shown in Figs. 6 and 8, the wave refraction effect for Ryori Bay will be strong when the wave period is shorter than approximately $7 \mathrm{~min}$. Consequently, the run-up heights of the wave with a period of 5 min simulated in the numerical experiment and the transfer functions for components higher than approximately $2.0 \times 10^{-3} \mathrm{~Hz}$ were insufficiently enhanced (Figs. 6, 8, and 9).

\section{A case study by considering the coastal structures}

The 2011 tsunami destroyed coastal structures such as dikes and fishery harbors in the vicinity of the head of Ryori Bay (Yamanaka et al. 2014). According to previous studies, coastal structures were effective in reducing the inundation due to the 2011 tsunami at some sites (e.g., Sozdinler et al. 2015; Adriano et al. 2016). Thus, the effect of coastal structures in Ryori Bay on the simulated run-up heights of the three tsunamis was investigated in this section. Coastal structures including the dike and the harbor 

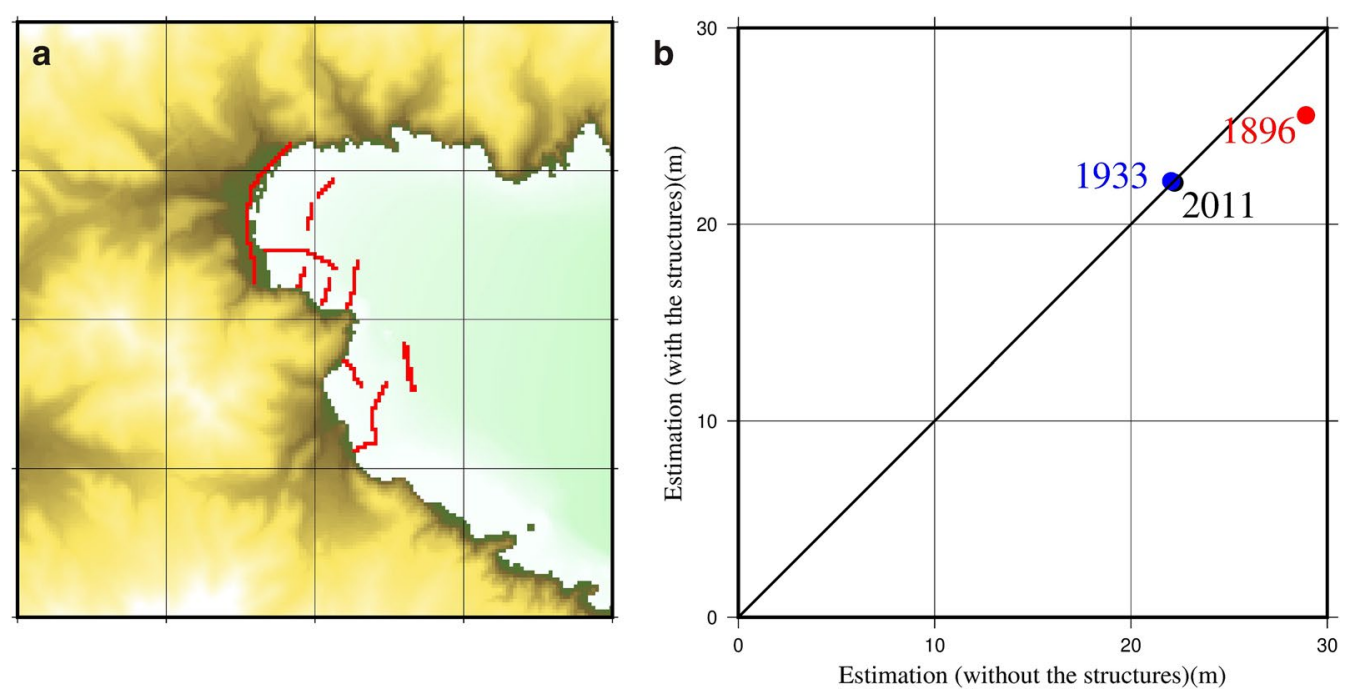

Fig. 10 a The coastal structures assumed in the computation domain (red); $\mathbf{b}$ the comparisons of the simulated maximum run-up heights for cases with and without the coastal structures. The black, blue, and red dots represent the 2011, 1933, and 1896 tsunamis, respectively. The horizontal coordinates, $X$ and $Y$, at the north-west corner of the domain in $\mathbf{a}$ are $-103,572.0 \mathrm{~m}$ and $84,042.0 \mathrm{~m}$ in the rectangular coordinate system and the grid-line interval for the figure is $500 \mathrm{~m}$

were created in the computation domain (Fig. 10a), and their heights were based on documents created after 1990 and provided by Iwate Prefecture. The crown height of the dike was assumed to be $8 \mathrm{~m}$ above sea level. However, the widths of all the structures in the domain may not be consistent with these documents because of limitations in the computation resolution. The incident boundary conditions for the three tsunamis were the same as those used in the simulation described in Chapter 2 (Fig. 4a). The present simulations assumed that the structures suffered no damage during the tsunamis and consequently, the results indicated that the structures remained fully intact even after the tsunamis. Figure 10b compares the simulation results based on the 12-m resolution domains with and without the coastal structures. Previous studies have highlighted the influence of coastal structure on the 2011 tsunami at specific sites; however, the figure shows an insignificant influence on the tsunami in the bay. As shown in Fig. 7, the water surface elevation during the tsunami was significantly higher than the crown height throughout the entire bay area because of its substantially long wavelength. In addition, a tsunami with a sufficiently long predominant period will overflow the dike for a long time, indicating that a large amount of the water will be deposited onto an area behind the dike. In this situation, the coastal structures might be inefficient. Nevertheless, despite the run-up height of the 1933 tsunami being insignificantly reduced due to the coastal structures, the run-up height of the 1896 tsunami was significantly reduced (Fig. 10b). As the predominant wave components in the two tsunamis were similar, i.e., $13 \mathrm{~min}$ and $9.3 \mathrm{~min}$, respectively (Fig. 5), the heights of the borelike wave might be responsible for this result. Larger flow velocities must have acted in the vicinity of the coastal structures as the bore height increased. As evident in Fig. 7, the height was likely larger in the 1896 tsunami than in the 1933 tsunami. Consequently, the structures might be efficient in reducing tsunamis with large flow velocities that are accelerated by bore generation. These features also indicate that tsunami damage in a region behind and near coastal structures is determined by the wave height, the period, the velocity associated with kurtosis of the wavefront, the structural condition of coastal structures, and the interactions of all these factors.

\section{Concluding remarks}

In the present study, the 2011 Tohoku, the 1933 Sanriku, and the 1896 Sanriku tsunamis propagating into Ryori Bay were investigated using numerical simulations to estimate the nearshore behaviors including inundation and run-up. The simulation results demonstrated that the 1933 and 1896 tsunamis consisted of critical frequency components for Ryori Bay. Moreover, the initial decrease in the water surface elevations affected the enhancement of the run-up heights. The results also indicated that the wavefronts of the two tsunamis under the influence of shoaling, narrowing bay width, and the nonlinear effect of the wave, became bore-like waves. The frequencydependent amplification characteristics of tsunamis in the bay were obtained via a numerical experiment and via 
analysis of the transfer functions. These results indicate that components ranging from approximately 7 to $10 \mathrm{~min}$ (from $2.3 \times 10^{-3}$ to $1.7 \times 10^{-3} \mathrm{~Hz}$ ) are amplified the most significant, while components at $7 \mathrm{~min}$ and shorter generate large refraction waves in the bay, resulting in an insufficient concentration of wave energy at the bayhead.

The results in the present study demonstrate that even small offshore tsunamis can cause large inundation and run-up when they propagate with critical wave components to a nearshore zone. Furthermore, tsunamis involving an initial decrease in water surface elevation and bore could further enhance coastal damage. Therefore, these results indicate that a tsunami following a relatively small earthquake with a magnitude (M) of approximately M8, as well as a tsunami following a large earthquake (approximately M9), can both cause equally severe inundations and large run-ups. Consequently, a tsunami following various earthquake scenarios including magnitudes of M7, M8, and M9 should be estimated for each local coastal area in order to develop appropriate tsunami disaster prevention strategies. Investigating local amplification features at other nearshore zones should be considered in future work.

\section{Supplementary information}

Supplementary information accompanies this paper at https://doi. org/10.1186/s40623-019-1128-1.

Additional file 1: Figure S1. The waveforms simulated in the large scale tsunami propagation simulations. Waveforms at site A specified in Fig. 1(b) based on the large scale tsunami propagation simulations using the linear long-wave model (solid lines) and the linear Boussinesq model (dashed lines). (a) the 2011 tsunami, (b) the 1933 tsunami, and (c) the 1896 tsunami.

\section{Abbreviations}

TTJS: The 2011 Tohoku Earthquake Tsunami Joint Survey Group; Mw: moment magnitude; M: magnitude; CMT: centroid-moment-tensor; GEBCO: General Bathymetric Chart of the Oceans.

\section{Acknowledgements}

We thank the editor and the two anonymous reviewers for their critical comments that have helped to improve the manuscript. We also thank Dr. Takenori Shimozono for his helpful discussions with us on the present study. All figures presented in this paper were printed using the Generic Mapping Tools (GMT) software of Wessel et al. (2013). The laser profiler measurements from the Japanese Government's Ministry of Land, Infrastructure, Transport and Tourism, were used to construct as the computation domains for the tsunami inundation simulations.

\section{Authors' contributions}

YY designed the concept of the present study and wrote the original draft of the manuscript. MN conducted the numerical simulations with YY and analyzed the simulation results. Both authors contributed to interpreting the results. Both authors read and approved the final manuscript.

\section{Funding}

The present study was supported by JSPS KAKENHI Grant Number 18H01541 and partially conducted within the framework of the JSPS Bilateral Joint Research Project (JSPS-STINT).

\section{Availability of data and materials}

The presented data are available from the corresponding author on request.

\section{Competing interests}

The authors declare that they have no competing interests.

Received: 2 September 2019 Accepted: 30 December 2019

Published online: 20 January 2020

\section{References}

Abe K (1973) Tsunami and mechanism of great earthquakes. Phys Earth Planet Inter 7:143-153

Abe K (1978) A dislocation model of the 1933 Sanriku earthquake consistent with the tsunami waves. J Phys Earth 26:381-396. https://doi. org/10.4294/jpe1952.26.381

Adriano B, Hayashi S, Gokon H, Mas E, Koshimura S (2016) Understanding the extreme tsunami inundation in Onagawa Town by the 2011 Tohoku Earthquake, its effects in urban structures and coastal facilities. Coast Eng J 58(4):1640013

Ammon CJ, Lay T, Kanamori H, Cleveland M (2011) A rupture model of the 2011 off the Pacific Coast of Tohoku earthquake. Earth Planets Space 63:33

Christensen DH, Ruff LJ (1988) Seismic coupling and outer rise earthquakes. J Geophys Res Solid Earth 93(B11):13421-13444. https://doi.org/10.1029/ JB093iB11p13421

Dziewonski AM, Anderson DL (1981) Preliminary reference earth model. Phys Earth Planet Inter 25:297-356. https://doi.org/10.1016/00319201(81)90046-7

Ekström G, Nettles M, Dziewonski AM (2012) The global CMT project 2004-2010: centroid-moment tensors for 13,017 earthquakes. Phys Earth Planets Inter 200:1-9. https://doi.org/10.1016/j.pepi.2012.04.002

Fujii Y, Satake K, Sakai S, Shinohara M, Kanazawa T (2011) Tsunami source of the 2011 off the Pacific Coast of Tohoku Earthquake. Earth Planet Space 63:815-820. https://doi.org/10.5047/eps.2011.06.010

Goda K, Yasuda T, Mori N, Mai PM (2015) Variability of tsunami inundation footprints considering stochastic scenarios based on a single rupture model: application to the 2011 Tohoku earthquake. J Geophys Res Oceans 120:4552-4575. https://doi.org/10.1002/2014JC010626

Goto C, Ogawa Y, Shuto N, Imamura F (1997) Numerical method of tsunami simulation with the leap-frog scheme. IOC Manuals Guides, No, p 35

Grilli ST, Harris JC, Bakhsh TST, Masterlark TL, Kyriakopoulos C, Kirby JT, Shi F (2013) Numerical simulation of the 2011 Tohoku tsunami based on a new transient FEM co-seismic source: comparison to far- and near-field observations. Pure Appl Geophys 170(6-8):1333-1359

Hibberd S, Peregrine DH (1979) Surf and run-up on a beach: a uniform bore. J Fluid Mech 95(2):323-345. https://doi.org/10.1017/S002211207900149X

Hossen MJ, Cummins PR, Dettmer J, Baba T (2015) Tsunami waveform inversion for sea surface displacement following the 2011 earthquake: importance of dispersion and source kinematics. J Geophys Res Solid Earth 120(9):6452-6473. https://doi.org/10.1002/2015JB011942

Kajiura K (1977) Local Behavior of Tsunamis. In: Provis DG, Radok R (eds) Waves on water of variable depth lecture notes in physics, vol 64. Springer, Berlin

Kanamori H (1971) Seismological evidence for a lithospheric normal faultingthe Sanriku earthquake of 1933. Phys Earth Planet Inter 4(4):289-300. https://doi.org/10.1016/0031-9201(71)90013-6

Kanamori H (1972) Mechanism of tsunami earthquakes. Phys Earth Planet Inter 6(5):346-359. https://doi.org/10.1016/0031-9201(72)90058-1

Koper KD, Hutko AR, Lay T, Ammon CJ, Kanamori H (2011) Frequency dependent rupture process of the 2011 Mw9.0 Tohoku earthquake: comparison of short-period P wave backprojection images and broadband seismic rupture models. Earth Planets Space 63:16

Liu PLF, Cheng Y (2001) A numerical study of the evolution of a solitary wave over a shelf. Phys Fluids 13(6):1660-1667. https://doi.org/10.1063/1.13666 66

Losada MA, Vidal C, Medina R (1989) Experimental study of the evolution of a solitary wave at an abrupt junction. J Geophys Res 94(10):14557-14566. https://doi.org/10.1029/JC094iC10p14557 
Løvholt F, Kaiser G, Glimsdal S, Scheele L, Haribitz CB, Pedersen GK (2012) Modeling propagation and inundation of the 11 March 2011 Tohoku Tsunami. Nat Hazard Earth Syst Sci 12(4):1017-1028

Madsen PA, Fuhrman DR, Schäffer HA (2008) On the solitary wave paradigm for tsunamis. J Geophys Res 113(C12012):1-22. https://doi. org/10.1029/2008JC004932

Miyoshi H (1987) True run-up heights reached by the huge tsunami of 1896. J Oceanogr Soc Jpn 43:159-168

Mori N, Takahashi T, Yasuda T, Yanagisawa H (2011) Survey of 2011 Tohoku earthquake tsunami inundation and run-up. Geophys Res Lett 38(7):LO0G14. https://doi.org/10.1029/2011gl049210

Obana K, Nakamura Y, Fujie G, Kodaira S, Kaiho Y, Yamamoto Y, Miura S (2017) Seismicity in the source areas of the 1896 and 1933 Sanriku earthquakes and implications for large near-trench earthquake faults. Geophys J Int 212(3):2061-2072

Okada Y (1985) Surface deformation due to shear and tensile faults in a halfspace. Bull Seismol Soc Am 75(4):1135-1154

Okal EA, Kirby SH, Kalligeris N (2016) The Showa Sanriku earthquake of 1933 March 2: a global seismological reassessment. Geophys J Int 206:14921514. https://doi.org/10.1093/gji/ggw206

Pelinovsky EN, Shurgalina EG, Rodin AA (2015) Criteria for the transition from a breaking bore to an undular bore. Izvest Atmos Ocean Phys 51(5):530-533

Romano F, Piatanesi A, Lorito S, D'Agostino N, Hirata K, Atzori S, Yamazaki Y, Cocco M (2012) Clues from joint inversion of tsunami and geodetic data of the 2011 Tohoku-oki earthquake. Sci Rep 2:385

Saito T, Furumura T (2009) Three-dimensional simulation of tsunami generation and propagation: application to intraplate events. J Geophys Res Solid Earth 114:B02307. https://doi.org/10.1029/2007JB005523

Saito T, Inazu D, Miyoshi T, Hino R (2014) Dispersion and nonlinear effects in the 2011 Tohoku-Oki earthquake tsunami. J Geophys Res Oceans 119:5160-5180. https://doi.org/10.1002/2014JC009971

Satake K, Fujii Y, Harada T, Namegaya Y (2013) Time and space distribution of coseismic slip of the 2011 Tohoku earthquake as inferred from tsunami waveform data. Bull Seismol Soc Am 103(2B):1473-1492. https://doi. org/10.1785/0120120122

Satake K, Fujii Y, Yamaki S (2017) Different depths of near-trench slips of the 1896 Sanriku and 2011 Tohoku Earthquakes. Geosci Lett 4:33. https://doi. org/10.1186/s40562-017-0099-y

Shimozono T (2016) Long wave propagation and runup in converging bays. J Fluid Mech 798:457-484. https://doi.org/10.1017/jfm.2016.327

Shimozono T, Sato S, Okayasu A, Tajima Y, Fritz HM, Liu H, Takagawa T (2012) Propagation and inundation characteristics of the 2011 Tohoku Tsunami on the Central Sanriku Coast. Coastal Eng J 54(1):1250004. https://doi. org/10.1142/S0578563412500040

Shimozono T, Cui H, Pietrzak JD, Fritz HM, Okayasu A, Hooper AJ (2014) Short wave amplification and extreme runup by the 2011 Tohoku tsunami. Pure Appl Geophys 171:3217-3228. https://doi.org/10.1007/s0002 4-014-0803-1

Sozdinler CO, Yalciner AC, Zaytsev A, Suppasri A, Imamura F (2015) Investigation of hydrodynamic parameters and the effects of breakwaters during the 2011 Great East Japan Tsunami in Kamaishi Bay. Pure Appl Geophys 172:3473-3491. https://doi.org/10.1007/s00024-015-1051-8

Sriram V, Didenkulova I, Sergeeva A, Schimmels S (2016) Tsunami evolution and run-up in a large scale experimental facility. Coast Eng 111:1-12

Suzuki T, Sasaki J, Tajima Y, Hayano K (2012) Field Survey of the 2011 of the Pacific Coast of Tohoku Earthquake Tsunami Disaster to the South of Iwate Prefecture. [In Japanese with English abstract]. J Jpn Soc Civil Eng Ser 68(2):25-30. https://doi.org/10.2208/jscejoe.68.i_25
Tadepalli S, Synolakis CE (1994) The run-up of N-waves on sloping beaches. Proc R Soc Lond A 445:99-112

Tanioka Y, Satake K (1996a) Fault parameters of the 1896 Sanriku Tsunami Earthquake estimated from Tsunami Numerical Modeling. Geophys Res Lett 23:1549-1552. https://doi.org/10.1029/96GL01479

Tanioka Y, Satake K (1996b) Tsunami generation by horizontal displacement of ocean bottom. Geophys Res Lett 23(8):861-864. https://doi. org/10.1029/96GL00736

Tanioka Y, Seno T (2001) Sediment effect on tsunami generation of the 1896 Sanriku Tsunami Earthquake. Geophys Res Lett 28(17):3389-3392

Tanioka Y, Ramirez AGC, Yamanaka Y (2018) Simulation of a Dispersive Tsunami due to the 2016 El Salvador-Nicaragua Outer-Rise Earthquake (Mw 6.9). Pure and Applied Geophysics 175(4):1363-1370. https://doi.org/10.1007/ s00024-018-1773-5

Tsuji Y, Satake K, Ishibe T, Harada T, Nishiyama A, Kusumoto S (2014) Tsunami heights along the Pacific Coast of Northern Honshu recorded from the 2011 Tohoku and previous great earthquakes. Pure Appl Geophys 171:3183-3215. https://doi.org/10.1007/s00024-014-0779-x

Uchida N, Kirby SH, Umino N, Hino R, Kazakami T (2016) The Great 1933 Sanriku-oki earthquake: reappraisal of the main shock and its aftershocks and implications for its tsunami using regional tsunami and seismic data. Geophys J Int 206:1619-1633. https://doi.org/10.1093/gji/ggw234

Weatherall P, Marks KM, Jakobsson M, Schmitt T, Tani S, Arndt JE, Rovere M, Chayes D, Ferrini V, Wigley R (2015) A new digital bathymetric model of the world's oceans. Earth Space Sci 2:331-345. https://doi. org/10.1002/2015EA000107

Wei Y, Chamberlin C, Titov W, Tang L, Bernard EN (2013) Modeling of the 2011 Japan tsunami: lessons for near-field forecast. Pure Appl Geophys 170(6-8):1309-1331

Wessel P, Smith WHF, Scharroo R, Luis JF, Wobbe F (2013) Generic mapping Tools: improved version released. Eos Trans AGU 94:409-410. https://doi. org/10.1002/2013EO450001

Yamanaka Y, Tajima Y, Sato S, and Liu H (2013) Dynamic Behaviors of the 2011 Tohoku Tsunami in Ryori Bay. In: Proceedings of 7th international conference on coastal dynamics. p. 1937-1946

Yamanaka Y, Sato S, Tajima Y (2014) Estimation of tsunami wave force on collapsed coastal Dyke in the Ryori Bay. [In Japanese with English abstract]. J Jpn Soc Civil Eng Ser 70(2):201-205. https://doi.org/10.2208/kaiga n.70.i_201

Yamanaka Y, Sato S, Shimozono T, Tajima Y (2018) A parametric study of tsunami fission generation in a Bay geometry based on numerical simulation. Coast Eng J 60(1):22-38. https://doi.org/10.1080/05785 634.2017.1418797

Yamanaka Y, Sato S, Shimozono T, Tajima Y (2019) A numerical study on nearshore behavior of Japan Sea tsunamis using green's functions for Gaussian sources based on linear Boussinesq theory. Coast Eng J 61(2):187-198. https://doi.org/10.1080/21664250.2019.1579462

Yeh H (1991) Tsunami bore runup. Nat Hazards 4:209-220

Yokota Y, Koketsu K, Fujii Y, Satake K, Sakai S, Shinohara M, Kanazawa T (2012) Joint inversion of strong motion, teleseismic, geodetic, and tsunami datasets for the rupture process of the 2011 Tohoku earthquake. Geophys Res Lett 38(7):L00G21. https://doi.org/10.1029/2011gl050098

\section{Publisher's Note}

Springer Nature remains neutral with regard to jurisdictional claims in published maps and institutional affiliations. 